\title{
ethic@ \\ [TRADUÇÃO] \\ CONTROVÉRSIA ENTRE THOMAS PAINE E EMMANUEL SIEYES SOBRE O CONCEITO DE GOVERNO REPRESENTATIVO ${ }^{1}$
}

\author{
Traduzido do original francês por
}

\author{
CRISTINA FORONI CONSANI ${ }^{2}$ \\ (UFPR/Brasil)
}

\begin{abstract}
RESUMO
Neste trabalho apresenta-se uma tradução do debate travado entre Emmanuel Sieyes e Thomas Paine acerca do conceito moderno de governo representativo.

Palavras-chave: Sieyes, Paine, governo representativo, república
\end{abstract}

\section{Carta de Emmanuel Sieyes,}

Paris, 6 de julho de 1791

This paper presents a translation of the debate between Emmanuel Sieyes and Thomas Paine on the modern concept of representative government.

Key words: Sieyes, Paine, representative government, republic

Paris, 6 de julho de 1791

Pensei que poderia passar minha vida sem jamais responder injúrias ou acusações sem provas. Quanto às injúrias, ainda não sinto a necessidade de prestar atenção a elas, por mais rica que fosse minha colheita neste gênero se me entretivesse recolhê-la. Quanto às acusações, pode ser de outra forma. Há circunstâncias em que é útil repeli-las. Por exemplo, propaga-se muito que estou aproveitando a nossa posição agora para voltar-me ao republicanismo. Diz-se que eu procuro fazer partidários desse sistema.

Até agora, eu não havia sido acusado de muita flexibilidade em meus princípios, nem de mudar minha opinião facilmente ao longo do tempo. Para homens de boa fé, os únicos aos 
quais eu posso me dirigir, há apenas três meios de julgar os sentimentos de alguém: suas ações, suas palavras e seus escritos. Eu ofereço esses três tipos de prova; elas não estão escondidas; elas já existiam antes da revolução, e tenho certeza de nunca ter me contradito. Mas se preferem confiar em alegações de calunia, tudo o que resta é calar-se.

Não é para alimentar velhos hábitos nem qualquer sentimento supersticioso de realismo que eu prefiro a monarquia. Eu a prefiro porque me é provado que há mais liberdade para o cidadão na monarquia do que na república. Qualquer outro motivo de determinação me parece pueril. O melhor regime social é, a meu ver, aquele no qual não um, não alguns somente, mas todos gozam tranquilamente a maior liberdade possível. Se eu percebo essa característica no estado monárquico, é claro que eu devo desejá-lo acima de qualquer outro. Eis o segredo dos meus princípios, e minha profissão de fé bem-feita.

Eu terei, talvez em breve, tempo para desenvolver esta questão. Entrarei na disputa com os republicanos de boa-fé. Eu não bradarei contra eles a impiedade, a execração; não vou dizerlhes injúrias. Conheço vários deles que honro e que amo de todo meu coração. Mas lhes darei razões, e espero provar, não que a monarquia é preferível a esta ou àquela posição, mas que, em todas as hipóteses, se é mais livre na monarquia do que na república. Neste momento, apresso-me em acrescentar, para que ninguém se engane, que minhas ideias a este respeito não são inteiramente aquelas que formam da monarquia os amigos da lista civil $^{3}$. Por exemplo, não penso que a faculdade de corromper e de conspirar seja um elemento necessário da verdadeira realeza. Eu acredito, ao contrário, que nada é mais próprio a prejudicá-la e perdê-la. Um ordenado público de trinta milhões é muito contrário à liberdade, e neste sentido muito antimonárquico, etc.

Permitam-me aproveitar esta ocasião para chamar a atenção daqueles que não duvidam que os homens que me chamam de republicano feroz são os mesmos que, por outro lado, tentam me fazer passar por monarquista contrarrevolucionário. À propósito, eles sempre sabem que tipo de linguagem é preciso ter com os diferentes partidos; sabe-se bem que o que eles querem não é dizer o que pensam, mas dizer aquilo que pode prejudicar. Este espírito é tão aperfeiçoado que vi aristocratas acusarem convenientemente de aristocracia um patriota de quem eles não gostavam; também os republicanos possuem o mesmo gênero de habilidade. Se esses homens soubessem como prejudicar o inimigo acusando-o de ser um homem honesto, eles o acusariam. 
Carta do Senhor Thomas Paine à M. Emmanuel Syeyes

Paris, 8 de julho de 1791

Senhor,

No momento de minha partida para a Inglaterra, eu li no Moniteur da última quarta-feira uma carta de vossa autoria, na qual o senhor propõe aos verdadeiros republicanos um desafio sobre o tema do Governo, e oferece-se para defender o que chama de opinião monárquica contra o sistema republicano.

Eu aceito com prazer o seu desafio, e tenho tanta confiança na superioridade do sistema republicano sobre essa nulidade de sistema chamado monarquia, que eu me comprometo a não exceder a extensão de cinquenta páginas, deixando-lhe a liberdade de tomar toda a latitude que lhe convier.

Meu respeito por sua reputação moral e literária é uma garantia de minha sinceridade em nossa discussão; mas, embora eu proponha conduzir-me com seriedade e boa-fé neste debate, devo, no entanto, avisá-lo que não pretendo privar-me da liberdade de ridicularizar, como merecem, os absurdos monárquicos, quando a oportunidade se apresentar.

Não entendo por republicanismo o que leva esse nome na Holanda e em alguns estados da Itália. Eu entendo por republicanismo simplesmente um governo por representação; um governo fundado sobre os princípios da Declaração de Direitos; princípios com os quais várias partes da Constituição francesa estão em contradição. As declarações dos direitos da França e da América são uma e a mesma coisa em princípio, e quase em expressão; e este é o republicanismo que me comprometo a defender contra o que é chamado de monarquia e de aristocracia.

Eu observo com satisfação que já estamos de acordo a respeito de um ponto - o extremo perigo de uma lista civil de trinta milhões. Não consigo ver nenhuma razão para uma parte do governo ser sustentada com tal extravagância, enquanto a outra mal recebe o suficiente para atender às suas primeiras necessidades. 
Essa desproporção perigosa e desonrosa fornece ao mesmo tempo para alguns o meio de corromper e para outros a posição de ser corrompido. Na América, fazemos pouca diferença entre a parte legislativa e a parte executiva de nosso governo, mas a primeira é muito melhor tratada do que na França.

De toda maneira, para que eu possa tratar do assunto do qual o Senhor propôs a discussão, espero que não duvide de minha estima por vós. Eu devo ainda acrescentar que não sou inimigo pessoal dos reis; ao contrário, ninguém deseja mais sinceramente do que eu vê-los no estado feliz e honrado de simples particulares. Mas eu sou o inimigo declarado, aberto e intrépido do que é chamado de monarquia, e o sou por princípios que nada pode alterar ou corromper. Pelo meu apego à humanidade, pela preocupação que eu tenho pela dignidade e pela honra da espécie humana, pelo desgosto que experiencio ao ver homens guiados por crianças e governados por brutos, pelo horror que me inspiram todos os males que a monarquia espalhou sobre a terra, a miséria, as extorsões, as guerras, os massacres com os quais arruinou a humanidade; por fim, é a todo o inferno da monarquia que eu declarei guerra.

Thomas Paine

$* * * *$

Nota explicativa de Emmanuel Sieyes, em resposta à Carta de Thomas Paine e a outras provocações do mesmo tipo

O senhor Thomas Paine é um dos homens que mais contribuiu para estabelecer a liberdade na América. Seu ardente amor pela humanidade, seu ódio por toda espécie de tirania, levou-o a assumir a defesa da Revolução Francesa na Inglaterra contra o discurso ambíguo do senhor Burke. O seu trabalho foi traduzido para a nossa língua sob o título de Os Direitos do Homem. Ele é universalmente conhecido; e qual patriota francês que, do fundo de sua alma, não agradeceu a este estrangeiro por ter fortalecido a nossa causa com todo o poder de sua razão e de sua reputação! É com grande prazer que encontro a oportunidade de oferecer-lhe o tributo de minha gratidão e de minha profunda estima pelo uso, verdadeiramente filantrópico, que ele faz de um talento tão distinto quanto o seu. 
O senhor Paine pressupõe que eu lhe propus um desafio, e ele o aceita. Eu não propus qualquer desafio, mas ficarei feliz em ter fornecido a um excelente autor a oportunidade de desenvolver mais algumas verdades.

O senhor Paine se declara abertamente contra o governo monárquico. Eu disse que o governo republicano me parecia insuficiente para a liberdade. Após uma declaração tão positiva de ambos os lados, parece que nos resta apenas mostrar nossas provas para o público, que estará pronto para realizar o seu julgamento. Mas, infelizmente, as questões abstratas, especialmente aquelas que pertencem a uma ciência cuja linguagem ainda não está estabelecida, precisam ser preparadas por uma espécie de convenção preliminar. Antes de iniciar uma contestação, pelo menos sob a insígnia da filosofia, é preciso ter certeza de que se será compreendido. O senhor Paine reconhece tão bem essa necessidade que ele quis começar apresentando suas definições.

Eu não compreendo, diz ele, por republicanismo, o que leva esse nome na Holanda e em alguns estados da Itália.

Ao escrever isso, o autor provavelmente pensou que, de minha parte, eu não gostaria de me comprometer em defender nem a monarquia otomana, nem a monarquia britânica.

Para ser razoável nesta discussão, e certamente ambos queremos sê-lo, devemos começar por dispensar todos os exemplos. No que diz respeito à ordem social, o senhor Paine não pode estar mais satisfeito do que eu com os modelos que a história nos oferece. A questão pode se estabelecer entre nós, portanto, apenas teoricamente. O senhor Paine sustentará sua república como ele a compreende. Eu defenderei a monarquia tal como a concebo.

Por fim, é a todo o inferno da monarquia que eu declarei guerra, escreve o senhor Paine. Exorto-o a acreditar que, nesta empreitada, quero ser seu auxiliar e não seu adversário, mas também gostaria de não poupar todo o inferno das repúblicas. Um é tão real quanto o outro e um não é melhor do que o outro. Não é possível que o senhor Paine e eu possamos ficar ao lado de qualquer tipo de inferno.

Por republicanismo, é o senhor Paine que fala, eu entendo simplesmente um governo por representação. Eu peço um pouco de atenção à minha resposta; tive alguma dificuldade em compreender porque se busca dessa maneira confundir dois conceitos tão distintos como aqueles do sistema representativo e do republicanismo.

Foi somente a partir do acontecimento do último dia 21 de junho ${ }^{4}$ que de repente vimos surgir um partido republicano. Qual é seu propósito? Pode ele ignorar que o plano de representação que a Assembleia Nacional apresentou à França, embora imperfeito em vários 
pontos, é, no entanto, o mais puro e o melhor que já apareceu sobre a Terra? Qual é então o objetivo daqueles que demandam uma república, definindo-a simplesmente como um governo por representação? Este partido, recém surgido, já se organizaria para atrair para si a honra de ter exigido o governo representativo contra a própria Assembleia Nacional? Ele tentaria seriamente convencer a todos que em tudo isso há somente duas opiniões: aquela dos republicanos, que querem uma representação, e aquela da Assembleia Nacional, que não a quer? Não, não podemos acreditar em tal quimera da parte dos senhores, os novos republicanos, nem esperar uma docilidade tão cega da parte do público e da posteridade.

Quando falo de representação política, vou além do Senhor Paine. Afirmo que toda constituição social da qual a representação não é a essência, é uma falsa constituição. Monárquica ou não, toda associação política, cujos membros não podem desobrigar-se ao mesmo tempo de toda administração comum, tem apenas que escolher entre representantes e senhores, entre o despotismo e um governo legítimo. Podem existir diversas maneiras de classificar os representantes, de coordená-los entre si, sem que nenhuma dessas diferentes formas possa atribuir a si exclusivamente o verdadeiro caráter essencial e distintivo de todo bom governo. Ele não parece ser alguém que começaria dizendo: Então, eu entendo por república o bom governo, e por monarquia o mau governo; aceite esta definição e defenda-se. Não é para um homem de intelecto como o senhor Paine que é preciso fazer uma advertência contra tal linguagem.

Que se dispute tanto quanto se queira os diferentes tipos de representação; que se examine, por exemplo, se é bom empregar exatamente o mesmo modo na ordem executiva e na ordem legislativa, e vinte outras questões desta natureza, mas disso não se segue que se deva vincular a essas nuances as diferenças que separam os monarquistas dos republicanos. Todos esses debates são ou serão comuns aos partidários dos dois sistemas, e eles o serão igualmente na dupla hipótese de uma boa ou má representação. De fato, quer os vossos procuradores escolhidos sejam bem ou mal eleitos, bem ou mal estabelecidos, resta saber qual será a sua correlação, e como serão ordenados entre si para a melhor distribuição e a maior facilidade de ação pública.

Em uma palavra, ainda será preciso saber se o que se deseja é uma república ou uma monarquia, porque por si mesmas as formas republicanas e as formas monárquicas se prestam tanto a uma boa quanto a uma má constituição, tanto a um bom quanto a um mal governo. Não é, portanto, nas características de uma verdadeira representação que convém buscar o atributo 
distintivo que assinala os republicanos. Eis aqui, na minha opinião, os dois pontos principais que permitem o reconhecimento da diferença entre os dois sistemas.

Faça terminar toda a ação política, ou isso que se apraz chamar de poder executivo, em um conselho de execução que delibera por maioria, e é nomeado pelo povo ou pela Assembleia Nacional: isso é a república.

Ao contrário, coloque-se à frente dos departamentos isso que se chama ministérios, e que devem ser melhor divididos, com chefes responsáveis, independentes uns dos outros, mas dependentes, por sua existência ministerial, de um indivíduo superior pela posição, representante da unidade estável do governo, ou, o que é o mesmo, da monarquia nacional, encarregada de eleger e revogar, em nome do povo, estes primeiros chefes de execução, e de exercer algumas outras funções úteis à coisa pública, mas sobre as quais a sua irresponsabilidade não pode ser perigosa: isso será a monarquia.

Vê-se que a questão depende quase inteiramente do modo de se coroar o governo. O que os monarquistas querem fazer por uma unidade individual, os republicanos o querem por um corpo coletivo. Eu não acuso os últimos de não perceberem a necessidade da unidade da ação; eu não nego que se possa estabelecer essa unidade em um senado ou no conselho superior de execução, mas eu penso que ela será aí mal constituída sob uma multidão de relatórios; eu penso que a unidade de ação precisa, para não perder nenhuma das vantagens que pode obter, não estar separada da unidade individual, etc.

Assim, em nosso sistema, o governo é composto por um primeiro monarca, eleitor e irresponsável ${ }^{5}$, em cujo nome atuam seis monarcas nomeados por ele e responsáveis. Abaixo estão as administrações dos departamentos, etc.

No outro sistema, no primeiro escalão de execução está um conselho ou senado nomeado pelos departamentos ou pela Assembleia Legislativa. Abaixo, as administrações dos departamentos, etc.

As pessoas que gostam de atribuir uma imagem às noções abstratas poderão imaginar o governo monárquico como aquele que acaba em um vértice, e o governo republicano em uma plataforma. Mas as vantagens que atribuímos a uma forma em detrimento da outra são tão importantes que vale a pena não se ater a uma simples imagem. Eu não vou desenvolver este ponto aqui pois não é o lugar, mas não receio repetir que é sobre os dois pontos que mencionei que é preciso situar o caráter distintivo dos dois sistemas, isto é, a diferença que existe entre uma decisão individual responsável, contida por uma vontade eleitora irresponsável, e uma 
decisão da maioria desobrigada de toda responsabilidade legal. As consequências serão deduzidas em outro lugar.

Poderíamos, além disso, os republicanos e nós, não concordar sobre muitas grandes questões do regime social, sem que houvesse por isso razão para encontrar tantas novas diferenças entre o republicanismo e o monarquismo. Por exemplo, pode-se apresentar várias combinações para eleger o conselho ou o senado de execução, com a intenção de ampliá-los mais ou menos sobre os corpos administrativos deliberativos. Da mesma forma, pode-se pensar que há mais de um modo apropriado de regular o que é chamado de sucessão ao trono; pois cada um é livre em sua opinião de ser republicano ou monarquista de muitas maneiras.

Se me perguntarem, e desconfio que perguntarão, o que penso sobre a hereditariedade do monarca eleitor, eu responderei sem hesitar que em boa teoria é falso que a transmissão hereditária de um ofício público, seja ele qual for, alguma vez possa concordar com as leis de uma verdadeira representação. A hereditariedade, nesse sentido, é tanto um ataque ao princípio quanto um insulto à sociedade.

Mas percorramos a história de todas as monarquias ou principados eletivos. Existe apenas um cujo modo de eleição não é ainda pior do que o modo hereditário? Quem será tão insensato para se atrever a culpar a conduta da Assembleia Nacional, para criticá-la por falta de coragem? O que poderiam fazer, há dois anos atrás, os homens que, no fundo, se assemelham muito aos outros, isto é, que julgam aquilo que a eles é oferecido pelo que eles sabem, e sabem, na maior parte, que só é possível o que já foi feito? Mesmo que eles tivessem considerado poder entrar no exame desta questão, teriam eles que estabelecer um equilíbrio entre a hereditariedade absurda, mas pacífica, e uma igualmente absurda eleição, frequentemente acompanhada de guerra civil? Hoje, na verdade, nos acostumamos ao modo eletivo, mas refletimos o suficiente para acreditar que pode existir uma grande variedade de combinações a este respeito. Há certamente uma delas muito aplicável à primeira função pública. Ela me parece reunir todas as vantagens atribuídas à hereditariedade, sem ter nenhum dos seus inconvenientes, todas as vantagens da eleição sem nenhum de seus perigos. No entanto, estou longe de pensar que a circunstância seja favorável para mudar neste ponto a Constituição decretada, e eu estou bastante confortável para assinalar fortemente minha opinião sobre este assunto.

Os obstáculos, eu espero, não são mais os mesmos; mas todos eles desapareceram e não surgiram novos? Uma divisão interior seria um mal indiferente neste momento? A Assembleia Nacional está segura da união de todas as partes da França para a Constituição já conhecida. 
Uma necessidade universal se faz sentir, de concluí-la e de assentá-la enfim por toda parte com uniformidade e com uma força capaz de consagrar o império da lei. Bem, seria razoável pegar esse momento para semear a discórdia entre os departamentos ${ }^{6}$, e arriscar incongruências nos decretos, para as quais seria tão difícil em seguida estabelecer os limites? De resto, se a nação quiser um dia se explicar, por uma Assembleia Constituinte, sobre o lugar do monarca, quer ele torne-se eletivo, quer ele permaneça hereditário, nós não perderemos por isso a monarquia, visto que haverá sempre o que a torna a essência, uma decisão individual, tanto da parte dos monarcas ativos quanto do monarca eleitor. Finalmente, espero que a opinião pública ao se esclarecer cada vez mais sobre questões políticas, perceba que geralmente o triângulo monárquico é mais apropriado do que a plataforma republicana a esta divisão de poderes que é o verdadeiro caminho da liberdade pública.

Eu entendo por república, é o senhor Paine que fala, um governo fundado sobre os princípios da Declaração de direitos. Eu não vejo porque esse governo não poderia ser uma monarquia.

Princípios, acrescenta ele, com os quais várias partes da constituição francesa se encontram em contradição. Isso pode ser verdade, e deve-se acreditar que se tivesse sido proposto fazer uma república, ainda teria sido possível cometer erros contra a Declaração de direitos. Mas quem não vê que essas contradições podem ser corrigidas sem que a França deixe de ser uma monarquia? Por fim, o senhor Paine me permitirá dizer-lhe uma segunda vez que, como eu não lhe peço para sustentar uma república em particular, é justo que ele me deixe a mesma liberdade relativamente à monarquia. Eu desejo que nossa discussão, se ela acontecer, não saia das esferas teóricas. As verdades que estabeleceremos poderão declinar, mais cedo ou mais tarde, para serem aplicadas aos fatos. Mas já dei a entender que neste momento eu senti muito mais a necessidade urgente de estabelecer a Constituição decretada do que aquela de reformá-la.

As declarações dos direitos da França e da América são uma e a mesma coisa em princípio, e quase em expressão. Lamentavelmente, eu gostaria que a nossa fosse melhor. Isso não seria difícil.

E este é o republicanismo que me comprometo a defender contra o que é chamado monarquia e aristocracia. Um homem que vive na França, na Europa, deve concordar que se tomarmos o sentido das palavras república e monarquia apenas na reputação que elas fizeram no mundo, há razão apenas para se enojar ao falar delas. Não teria eu a oportunidade, se eu quisesse seguir o exemplo dado a mim pelo senhor Paine, de desfavorecer o que é chamado de 
república e de aristocracia? Quem sabe mesmo se, desde já e por maioria dos votos, não se encontraria maior probabilidade à aliança que eu ataco do que àquela que a princípio me é oposta? De boa-fé, um senado de execução seria menos aristocrático do que ministros agindo sob a eleição livre e irresponsável de um monarca, cujo interesse evidente e palpável seria sempre, mas sempre, inseparável daquele da maioria? Eu posso estar errado em já deixar escrutinar minhas dúvidas sobre a virtude do sistema republicano. Quão longe estão de me entender aqueles que me acusam de não adotar a república, que acreditam que não ir tão longe é parar na metade do caminho. Nem as ideias nem os sentimentos que são chamados republicanos me são desconhecidos; mas no meu propósito de avançar sempre em direção à máxima liberdade social, eu tive que passar a república, deixá-la para trás, e alcançar enfim a verdadeira monarquia. Se estou errado, declaro, pelo menos, que não é falta de atenção nem falta de tempo, porque minhas pesquisas e minhas conclusões precederam a Revolução.

Eu reconheço que, para uma nota, isso tornou-se um pouco longo, e eu peço desculpas, mas eu queria evitar, se a discussão ocorrer, que ela degenere em uma disputa de palavras. Acredito que resulta, do que acaba de ser lido, que os homens, ciosos de falar uma linguagem precisa, não se permitirão tomar o republicanismo pelo oposto do monarquismo. O correlativo de um é muitos. Nossos adversários são os poliarquistas, os policrates, esse é o seu verdadeiro título. Quando se dizem republicanos, não deve ser em oposição à monarquia, mas sim porque eles são favoráveis à coisa pública, contra a coisa privada; certamente, nós também. O interesse público, é verdade, há muito tempo tem sido sacrificado pela coisa particular; mas esse infortúnio não tem sido comum a todos os estados conhecidos, independentemente de suas diversas denominações? Se, ao invés de adotar noções claras, favoravelmente preparadas pela própria etimologia, persistirmos em uma confusão de palavras que não nos parecem úteis para nada, sem dúvida eu não me oporia obstinadamente; eu permitiria que o termo república fosse empregado como sinônimo de constituição representativa; mas eu declaro que, após tê-lo compreendido neste sentido, eu sentiria ainda a necessidade de perguntar se, afinal, queremos que nossa república seja monárquica ou poliárquica. Estabeleçamos, então, se necessário, a questão nesses termos: "Em uma boa república, é melhor que o governo seja poliárquico do que monárquico?"

Terminarei esta resposta com uma observação que eu deveria ter colocado no início. Minha carta inserida no Moniteur de 6 de julho não anuncia que tenho o tempo livre para entrar na controvérsia com os republicanos policrates. Minhas expressões são: “Eu terei, talvez em breve, tempo de desenvolver esta questão, etc.” Por que em breve? Porque sempre me convenço 
que a Assembleia nacional irá dar brevemente os últimos retoques à sua obra, e que ela está prestes a terminar. Até lá, me é impossível deixar minhas ocupações diárias para preencher os jornais com qualquer tipo de discussão. Respondem-me que esta questão está na ordem do dia. Isso é o que eu não vejo. Além disso, um amigo da verdade não gosta de tratar questões de direito sob a influência das questões de fato. A busca de princípios e sua publicação já é suficientemente laboriosa, principalmente a um homem abandonado às suas próprias forças individuais, para que ele não se exponha ao arrependimento por ter apresentado razões em circunstâncias em que as vontades muito determinadas não deixam que a faculdade aí lhe dê ouvidos e, finalmente, tenha conseguido servir, a despeito de si mesmo, aos propósitos de um ou de outro partido.

EMM. SIÈYES 


\section{Notas}

${ }^{1}$ A tradução do francês para o português foi realizada a partir dos textos publicados em Réimpression de L'Ancien Moniteur (Mai 1789 - Novembre 1799), Tomo IX, Paris: Imprimerie D’A. René et Cie, 1842. A Carta de Emmanuel Sieyes, de 6 de julho de 1791, está nas páginas 46 e 47. A carta de Thomas Paine e a resposta de Sieyes encontram-se nas páginas 137 a 139. A obra está em domínio público.

${ }^{2}$ Professora Adjunta no Departamento de Filosofia da Universidade Federal do Paraná.

${ }^{3}$ N. T: Lista civil é um termo utilizado para designar uma dotação anual atribuída pelo Estado para as despesas da realeza. Esse instrumento permitiu distinguir as despesas da coroa no orçamento do Estado. Trata-se de um instituto auxiliar na limitação do poder absoluto do monarca, pois abre a possibilidade de o poder legislativo controlar os gastos da monarquia. A lista civil, que já era utilizada na Inglaterra, passou a ter sua criação discutida na França após a Revolução e foi instituída entre 1790 e 1791. Cf. GAUTIER, Alphonse. Etudes sur la Liste Civile en France. Paris: E. Plon et Cie. Imprimeurs-Editeurs, 1882, p. 2-14.

${ }^{4}$ N.T: O acontecimento ao qual Sieyes se reporta é a tentativa frustrada de fuga de Luís XVI e de sua família, ocorrida entre os dias 20 e 21 de junho de 1791.

${ }^{5}$ N.T: O termo irresponsável aqui significa que o monarca não é responsável no sentido político, isto é, significa que ele não pode ser retirado do cargo a partir de uma avaliação negativa por parte do povo, haja vista ele não possuir um mandato eletivo, com prazo determinado e cuja renovação depende da aprovação dos eleitores.

${ }^{6}$ N. T: Departamentos são divisões administrativas do Estado francês. 